\title{
Análise da competitividade da indústria marítima brasileira - associação dos fatores críticos de sucesso com suas dimensões
}

\author{
Delmo Alves de Moura ${ }^{a *}$, Rui Carlos Botter ${ }^{\mathrm{b}}$ \\ a*delmo.moura@ufabc.edu.br, UFABC, Brasil \\ brcbotter@usp.br, USP, Brasil
}

\begin{abstract}
Resumo
Esta pesquisa analisa a competitividade da indústria marítima brasileira focada nos segmentos da construção naval, reparo naval, construção de plataforma/FPSO e construção náutica, turismo, lazer e recreação. 0 estudo buscou definir os fatores críticos de sucesso da indústria marítima brasileira e fazer a associação com suas respectivas dimensões. Utilizaram-se, como parâmetros, os modelos de dimensões propostos por Slack (1993), Bolwijn e Kumpe (1990). Foram realizadas pesquisas em campo nos 31 estaleiros brasileiros e buscou-se associar os fatores críticos de sucesso com as dimensões definidas na literatura e analisar o estágio de competitividade da indústria marítima brasileira. Dentre as principais conclusões avalia-se que existam nichos específicos que podem tornar o Brasil competitivo e promover o crescimento da indústria marítima doméstica.
\end{abstract}

Palavras-chave

Indústria marítima brasileira. Competitividade. Fatores críticos de sucesso.

\section{Introdução}

Atualmente no Brasil existe uma demanda latente para o segmento da construção naval, em virtude da necessidade da renovação da frota da empresa Transpetro, subsidiária da Petrobras, e a própria exploração futuramente da camada pré-sal. Esse é um dos segmentos inerentes à indústria marítima nacional, mas há pelo menos mais três segmentos que compõem essa indústria no país: de reparo naval, de construção de plataforma/UEP e o segmento náutico, turismo, esporte e lazer.

Esta pesquisa foi aplicada in loco em 31 estaleiros brasileiros referentes aos quatro segmentos principais da indústria marítima nacional. 0 total de estaleiros visitados corresponde à maioria da capacidade produtiva do cenário brasileiro, além de representar a quase totalidade do faturamento dos setores. A pesquisa foi também fundamentada num estudo anteriormente desenvolvimento pela Universidade de Michigan, nos Estados Unidos, adaptado para as condições nacionais, que avaliou as melhores práticas mundiais na indústria naval (FLEISCHER, 1999).

Aplicou-se um questionário composto por 232 questões para avaliar o estágio atual da indústria marítima brasileira e definir a relação/associação dos fatores críticos de sucesso (FCSs) dessa indústria com suas respectivas dimensões, custos, qualidade, flexibilidade, tempo, credibilidade e inovação. Como proposto nos modelos de Slack (1993) e Ferdows e De Meyer (1990) para avaliar a competitividade de uma determinada indústria ou empresa.

0 objetivo deste trabalho foi avaliar a competitividade da indústria marítima. Nesta pesquisa, o foco são quatros setores: construção naval, reparo naval, construção de plataforma e construção náutica. 0 estudo procura aplicar os modelos de competitividade de Slack (1993) e Ferdows e De Meyer (1990) e analisar a associação 
dessas dimensões com os fatores críticos de sucesso definidos pelos próprios estaleiros.

A contribuição deste estudo é definir os fatores críticos que são essenciais para promover a competitividade dos estaleiros nacionais e consequentemente contribuir para a indústria marítima doméstica.

\section{Fundamentação teórica da pesquisa}

Para Slack (1993), a vantagem competitiva em manufatura demonstra um diferencial que a empresa possui frente a seus concorrentes para atender às necessidades do mercado. Isso significa que fazer correto está relacionado ao objetivo de desempenho qualidade, fazer rápido com o objetivo velocidade, fazer pontualmente com o objetivo credibilidade, customizar com o objetivo flexibilidade e fazer com o menor custo com o objetivo custo.

A Figura 1 descreve a adaptação criada por Slack (1993), fundamentada no modelo do cone de areia proposto por Ferdows e De Meyer (1990), para descrever um modelo do conceito de cumulatividade. Dessa forma, busca-se o melhor desempenho no objetivo de desempenho qualidade e, consequentemente, procura estruturar-se para atingir melhoria no item credibilidade. Atingindo os níveis necessários para os itens qualidade e credibilidade, uma empresa deve dedicar esforços para os itens velocidade e flexibilidade. Após os quatro objetivos de desempenho bem estruturados, uma empresa deve focar no item custos. 0 autor considera em seu modelo tanto os aspectos internos como externos de uma empresa, quando utiliza os cinco objetivos de desempenho relacionados com a vantagem competitiva em manufatura.

Outro modelo que aparece na literatura é o de fase de Bolwijn e Kumpe (1990). A Figura 2 descreve a concepção dos fatores criados pelos dois autores, que analisaram as mudanças ocorridas ao longo do tempo no ambiente competitivo e focaram nos seguintes itens como diferencial competitivo para uma empresa:

Custos: Uma empresa considerada de excelência buscava a redução de seus custos, fruto da redução da economia norte-americana na década de 60 . Custo passou a ser diferencial competitivo, visto a concorrência severa entre as empresas para manter ou aumentar sua parcela de mercado.

Qualidade: A inserção dos produtos japoneses no mercado global, com qualidade assegurada e sem aumento de custos dos produtos, faz com

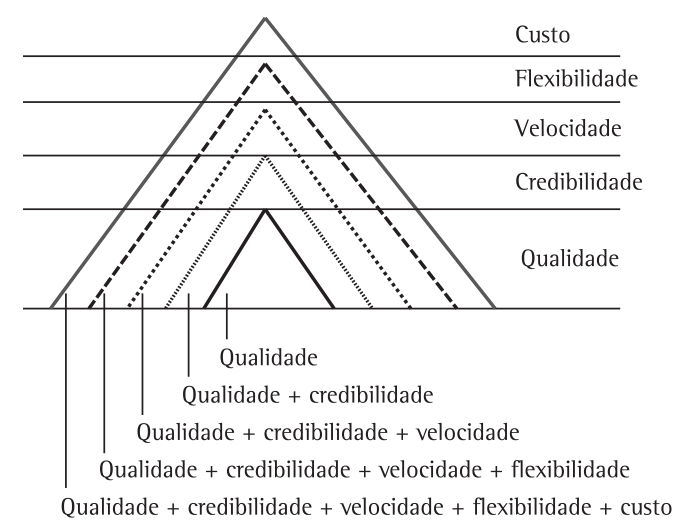

Figura 1. Modelo de competitividade de Slack (1993), adaptado do modelo de cone de areia.

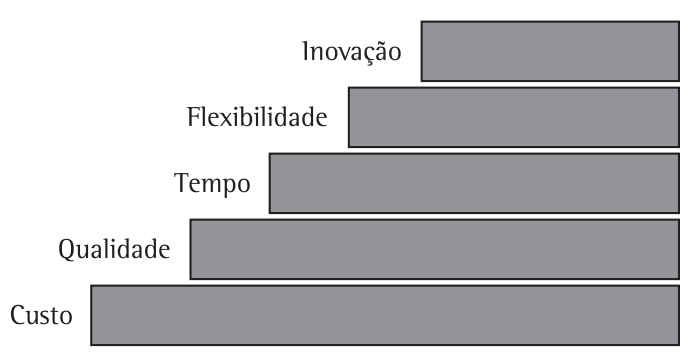

Figura 2. Modelo de fases de Bolwijn e Kumpe (1990).

que esse fator pressione a concorrência para inserir essa dimensão também em seus produtos, já que o mercado consumidor passa a valorizar essa variável. lsso ocorre durante a década de 70 .

Tempo: Fato como o lançamento de novos produtos no mercado obriga as empresas a se estruturarem bem na dimensão tempo, reduzindo o desenvolvimento de novos projetos e, consequentemente, sua produção. Isso acontece no início da década de 80 .

Flexibilidade: Lançar novos produtos e, com isso, oferecer alta diversificação ao mercado pela dimensão ou variável flexibilidade de projeto, processo de produção, da cadeia de suprimentos etc. Essa dimensão passa a ser um diferencial competitivo para as empresas. Também ocorre no início da década de 80 .

Algumas definições que caracterizam as dimensões ou prioridades competitivas, como descrevem diversos autores (SKINNER, 1969; HAYES; WHEELWRIGHT, 1984; SLACK, 1993; MORAES, 2003; MAIA; CERRA; ALVES FILHO, 2005), podem assim ser resumidas: 
Custos: Custos baixos podem permitir preços baixos, auxiliando na competitividade dos produtos quando ofertados ao mercado. Dessa forma, a busca constante de redução de custos pode auxiliar positivamente na lucratividade de uma empresa.

Qualidade: De forma ampla está associada à qualidade do produto e processo, e envolve diversos fatores relacionados com a satisfação dos clientes, o que inclui também o serviço pós-venda, além de produtos sem erro, conforme as características definidas pelo projeto.

Flexibilidade: É a capacidade de adaptar-se às mudanças, que podem ocorrer seja na demanda, no fornecimento, no processo produtivo, na tecnologia empregada, nos roteiros de produção, como em outros elementos que compõem o ambiente da manufatura.

Inovação: Habilidade de fazer mudanças e de usar a criatividade para melhorar métodos, processos e produtos, assim como lançar novos produtos no mercado.

Tempo: Pode se relacionar com o desenvolvimento de projetos, de novos produtos ou com produção propriamente dita da manufatura. Entregar os produtos com mais rapidez pode tornar-se um critério de decisão para conquistar mercados, e alguns clientes, muitas vezes, estão dispostos a pagar um preço superior ao mercado quando percebem oportunidades de obter seus pedidos com maior velocidade de entrega.

Credibilidade: De entrega visando a redução de estoques. Portanto, na medida em que as empresas ficam mais dependentes de sua cadeia de suprimentos no tempo certo, a garantia de que as encomendas serão recebidas nos prazos combinados (credibilidade de entrega) torna-se de grande valor na escolha de seus fornecedores. 0 intuito é ter 0 processo confiável sem gerar estoque na cadeia de suprimentos.

\subsection{Definições de fatores críticos de sucesso}

$\mathrm{Na}$ literatura, o pioneiro a discorrer sobre fatores de sucesso foi Daniel. 0 autor relata que uma organização deveria definir quais são os fatores de sucesso para seu negócio e com isso determinar quais são as forças e fraquezas relacionadas com esses fatores para poder mensurar suas vantagens frente a seus concorrentes (DANIEL, 1961; MARCHAND; RAYMOND, 2008).

Uma equipe do Massachusetts Institute of Technology (MIT), coordenada por John F.
Rockart, no final da década de 70, implantou uma metodologia referente aos fatores críticos de sucesso para auxílio dos executivos na tomada de decisão. Essa metodologia tem como base definir as principais informações relevantes para cada organização, do ponto de vista de seus executivos, e permear essas informações por toda empresa com o objetivo de todos atuarem na mesma direção e sentido, para alcançarem os resultados almejados.

Os fatores críticos de sucesso foram definidos como áreas ou atividades empresariais que devem receber uma atenção especial da gestão da organização, para que os resultados sejam alcançados, visando a uma vantagem competitiva frente aos concorrentes (ROCKART, 1979). Rockart descreve que a análise dos fatores críticos de sucesso de uma empresa abrange tanto o ambiente interno como o externo, envolve os fatores críticos de sucesso da indústria ao qual a empresa está inserida (fatores externos) e aos seus próprios fatores críticos de sucesso (fatores internos).

Os autores Bergeron e Bégin (1989) descrevem que um dos pontos-chave para determinar os fatores críticos de sucesso de uma empresa seria a entrevista com os executivos da empresa, conforme definiu Rockart nos estudos realizados pelo MIT.

Segundo Magnani (2004), fatores críticos de sucesso diferem de competências e recursos. Ele descreve que competências e recursos são fatores essenciais para estar no mercado, mas que não necessariamente caracterizam as diferenças nos valores criados para as organizações.

Conforme Amberg et al. (2005), pela definição de Rockart (1979), fundamentada na ideia de Daniel (1961), o fator crítico de sucesso pode ser explicado como um número limitado de áreas, cujos resultados, se eles são satisfatórios, assegurarão desempenho competitivo de sucesso para uma organização.

Leidecker e Bruno (1984) definem fatores críticos de sucesso como aquelas características ou variáveis que, quando propriamente sustentadas, mantidas ou gerenciadas, podem ter um impacto significativo para o sucesso de uma empresa que compete numa determinada indústria.

Para os autores Hofer e Schendel (apud QUINTELLA et al., 2005), os fatores críticos de sucesso são variáveis onde a gerência de uma organização pode influenciá-las, interferindo na posição que uma empresa possui dentro de uma determinada indústria. 
Para Putri e Yusof (2009), fatores críticos de sucesso para a Engenharia da Qualidade podem ser definidos como fatores necessários para assegurar efetivamente a implantação de um sistema que garanta a qualidade do produto em todas as etapas de seu ciclo, desde o desenvolvimento do projeto até a fase final da manufatura do produto.

Segundo King e Burgess (2006), os fatores críticos de sucesso devem ser analisados não de forma estática e individual, e sim de maneira global, avaliando-se o impacto no desempenho operacional e na melhora da produtividade de uma organização.

Para Salaheldin (2009), os fatores críticos de sucesso podem ser definidos como áreas críticas de uma empresa que merecem atenção especial para que ela alcance seus objetivos e torne-se competitiva em seu segmento de atuação.

\subsection{Justificativas dos fatores críticos de sucesso utilizados nesta pesquisa}

Os fatores críticos de sucesso (FCSs) foram definidos da seguinte forma:

a) Utilizou-se como base o relatório denominado Shipbuilding Supply Chain Integration Projetct, de 1999, desenvolvido pelo ERIM (Environmental Research Institute of Michigan) e UMTRI (University of Michigan Transportation Research Institute), cujos autores são Mitchell Fleisher, Ronald Kohler (ERIM), Thomas Lamb, H. Bruce Bongiorni (UMTRI) e Nathan Tupper (Independent Consultant). Esse relatório, especializado no segmento da construção naval, serviu como parâmetro para determinar diversos fatores críticos de sucesso utilizados no questionário aplicado em campo na indústria marítima brasileira.

0 relatório desenvolvido pela Universidade de Michigan caracteriza Best Practices como um diferencial competitivo para uma empresa de sucesso, e essa mesma concepção foi utilizada para definir os fatores críticos de sucesso da pesquisa realizada no Brasil, adaptando-a para a realidade nacional, visto que a pesquisa desenvolvida pela Universidade de Michigan envolvia empresas norteamericanas, europeias e asiáticas.

0 relatório de Michigan é fundamentado numa pesquisa em campo com executivos e gerentes de engenharias relacionados com o segmento da construção naval, os estaleiros, fornecedores de navipeças e uma empresa não relacionada com a indústria marítima. Os pesquisadores visitaram 10 estaleiros: quatro instalados nos Estados Unidos, três na Europa e três na Ásia. Os estaleiros visitados não eram exclusivamente do mesmo segmento. Também foram visitados 10 fornecedores, sendo: dois instalados nos Estados Unidos, seis na Europa, um no Japão e um com unidade de negócio nos Estados Unidos e também no Japão.

$\mathrm{Na}$ pesquisa realizada pela Universidade de Michigan uma empresa não fazia parte da indústria marítima, mas ela foi relacionada no trabalho por ter muita semelhança, na forma de gestão da produção, operações e desenvolvimento de produto, com os estaleiros das pesquisadas (sistemas de produção de grandes projetos).

As melhores práticas descritas no relatório desenvolvido pela Universidade de Michigan foram estruturadas da seguinte forma: estratégia da cadeia de suprimentos, planejamento da cadeia de suprimentos, mecanismos de controle entre estaleiros e sua cadeia de suprimentos e sistemas de integração entre as partes envolvidas.

Sendo assim, os fatores críticos de sucesso utilizados na pesquisa no Brasil foram inicialmente extraídos das melhores práticas de cada subitem do relatório desenvolvido pela Universidade de Michigan e adaptados à realidade brasileira.

Os fatores críticos de sucesso extraídos do relatório elaborado pela Universidade de Michigan foram previamente adaptados para a realidade brasileira e apresentados para diversos executivos, proprietários, diretores etc. de alguns estaleiros no Brasil para saber se aqueles fatores eram relevantes para mensurar a competitividade da indústria marítima brasileira (KATHURIA et al., 2008; PRAJOSO; McDERMOTT; GOH, 2008).

Os fatores críticos de sucesso foram associados com as dimensões propostas pelos modelos de Slack (1993) e Bolwijn e Kumpe (1990) para avaliar a competitividade dos estaleiros domésticos. 0 intuito foi analisar com quais dimensões os fatores críticos de sucesso estavam mais associados, quando se avalia a competitividade da indústria marítima brasileira.

Segundo Tontini e Sant'ana (2007), um atributo que tiver alta importância, mas baixo desempenho, deverá receber atenção imediata (quadrante IV: necessidade de melhoria), conforme Figura 3. Para aumentar a satisfação geral, os dirigentes da empresa deveriam concentrar-se para melhorá-lo. 0 quadrante 111 (neutralidade) contém os atributos com baixa importância e baixo desempenho, não sendo necessário concentrar esforços adicionais. 0 quadrante 11 (baixa relevância) apresenta os atributos com alto desempenho, porém com 


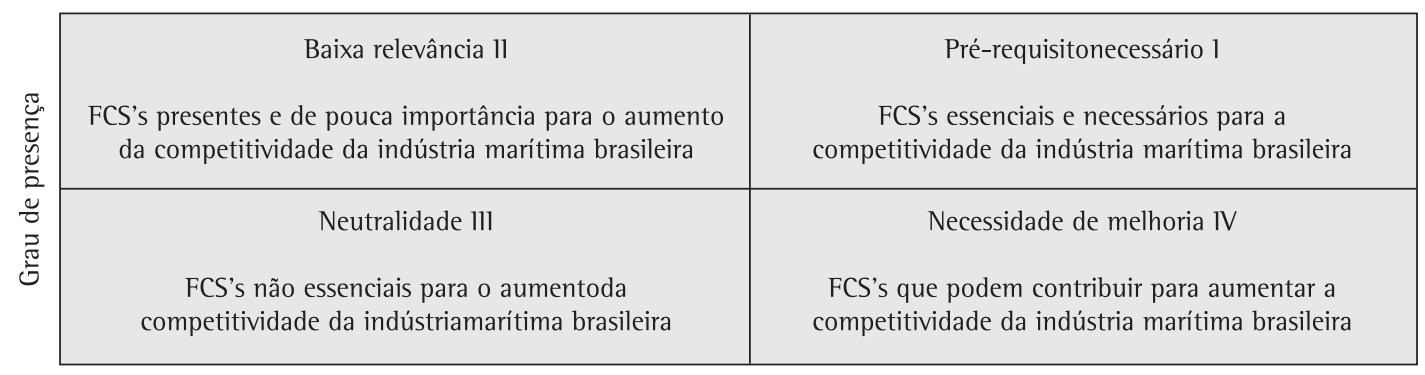

Importância

Figura 3. Mapa de importância dos quadrantes de competitividade.

baixa importância que contribua para o resultado final. Essa análise é comumente conhecida como matriz de desempenho ou grau de presença versus importância ou análise de quadrantes e tem grande utilidade em pesquisas de marketing (Figura 3) (MYERS, 1996).

\section{Metodologia utilizada}

Consistiu da pesquisa do tipo qualitativa (MATTAR, 1999; COOPER; SCHINDLER, 2003; BABBIE, 2001; SELLTIZ; WRIGHTSMAN; COOK, 1987; BOTELHO; ZOUAIN, 2006). Ela foi realizada por meio de entrevistas pessoais, in loco, com empresários, presidentes, diretores e gerentes atuantes na indústria marítima nacional. Foram realizadas visitas nos estaleiros do segmento da construção naval e da atividade offshore (produção de plataforma ou UEPs, unidades estacionárias de produção de petróleo e navio FPSO), indústria militar, pesca industrial, construção fluvial e dragagem, construção náutica, turismo, recreação e lazer, empresas de máquinas e equipamentos, associações de classe, classificadoras e certificadoras de embarcação, empresas de navegação, marinas e equipamentos portuários. 0 critério utilizado para seleção das empresas nas pesquisas qualitativas foi baseado na importância da empresa dentro de seu segmento.

0 questionário foi aplicado em 31 estaleiros, conforme Tabela 1; outras informações também foram coletadas pessoalmente em outros atores da indústria marítima nacional, como os fornecedores da indústria da construção naval e náutica (cadeia de suprimentos), além de algumas visitas técnicas internacionais a estaleiros no exterior e na associação de cluster marítimo holandês em Roterdã.

Todos os dados foram coletados por meio de entrevistas pessoais e nada foi coletado via telefone,
Tabela 1. Quantidade de estaleiros visitados in loco.

\begin{tabular}{lc}
\hline Setor & $\begin{array}{c}\text { Quantidade } \\
\text { de estaleiros } \\
\text { visitados } \\
\text { pessoalmente }\end{array}$ \\
\hline Construção e reparo naval e offshore & 17 \\
Construção náutica, turismo, recreação e lazer & 14 \\
Total & 31 \\
\hline
\end{tabular}

internet, por e-mail etc. 0 questionário sempre foi aplicado pelo mesmo pesquisador, especialista da área, e foram mais de oito meses de coleta de dados em campo, nos estaleiros com unidade de produção pelo Brasil.

0 questionário é extenso e abrangeu 232 questões. Demandou, muitas vezes, mais de uma visita ao mesmo estaleiro e em áreas diferentes para a coleta de dados. As questões, na sua maioria, foram fechadas.

Usou-se a escala de Likert, como apresentada no Quadro 1.

0 questionário foi elaborado de forma que as questões relacionadas com os fatores críticos de sucesso, definidas pelos próprios estaleiros, fossem relacionadas com as dimensões em estudo. As respostas dos entrevistados foram associadas com uma escala Likert. 0 próprio entrevistado definiu a pontuação que melhor se enquadrava dentro de seu estaleiro para avaliar a competitividade e o grau de aderência dos fatores críticos de sucesso com as dimensões. 0 Quadro 1 exemplifica parte do questionário aplicado em campo (232 questões).

0 questionário sempre foi aplicado aos presidentes, diretores e gerentes dos estaleiros. A gerência envolvia as seguintes áreas: de produtos, de processos industriais e do setor comercial. Porém, nem todos os estaleiros visitados possuíam essas áreas bem definidas, e a entrevista acontecia com seus diretores ou presidentes. 
Quadro 1. Exemplo do questionário aplicado em campo.

\begin{tabular}{|c|c|c|c|c|c|c|c|}
\hline \multirow{2}{*}{ Fatores } & \multicolumn{3}{|c|}{ Discordo } & \multicolumn{3}{|c|}{ Concordo } & \multirow{2}{*}{$\begin{array}{l}\text { Não } \\
\text { sabe }\end{array}$} \\
\hline & * & & & & & $*$ & \\
\hline Existe um sistema de qualificação de fornecedores no meu estaleiro & $(1)$ & $(2)$ & $(3)$ & $(4)$ & (5) & (6) & (9) \\
\hline Existe terceirização de produtos que eram fabricados internamente pelo estaleiro & (1) & $(2)$ & (3) & (4) & (5) & (6) & (9) \\
\hline Existe terceirização de serviços que eram realizados pelo estaleiro & (1) & $(2)$ & (3) & (4) & (5) & (6) & (9) \\
\hline Existe uma área de pesquisa e desenvolvimento de produtos no meu estaleiro & $(1)$ & $(2)$ & (3) & $(4)$ & (5) & (6) & (9) \\
\hline Realizo estudos de nacionalização de produtos/componentes/peças no meu estaleiro & $(1)$ & $(2)$ & $(3)$ & $(4)$ & (5) & (6) & (9) \\
\hline Meus equipamentos industriais e máquinas encontram-se tecnologicamente atualizados & $(1)$ & $(2)$ & $(3)$ & $(4)$ & (5) & (6) & (9) \\
\hline Os meus fornecedores participam da fase inicial do desenvolvimento do projeto & (1) & (2) & (3) & (4) & (5) & (6) & (9) \\
\hline $\begin{array}{l}\text { Existe parceria tecnológica na área de pesquisa e desenvolvimento entre os meus } \\
\text { fornecedores e o meu estaleiro }\end{array}$ & (1) & (2) & (3) & (4) & (5) & (6) & (9) \\
\hline $\begin{array}{l}\text { Existe parceira tecnológica ou financeira para melhoria de processos, capacitação técnica } \\
\text { e outros entre os meus fornecedores e o meu estaleiro }\end{array}$ & (1) & (2) & (3) & (4) & (5) & (6) & (9) \\
\hline $\begin{array}{l}\text { Mensuro o comprometimento dos meus fornecedores com o prazo de entrega através } \\
\text { de mecanismos de controle }\end{array}$ & (1) & (2) & (3) & (4) & (5) & (6) & (9) \\
\hline $\begin{array}{l}0 \text { abastecimento de peças/componentes provenientes dos meus fornecedores nacionais } \\
\text { é padronizado }\end{array}$ & (1) & (2) & (3) & (4) & (5) & (6) & (9) \\
\hline
\end{tabular}

* Totalmente.

\subsection{Estaleiros entrevistados por segmento}

Os estaleiros foram identificados pelas suas respectivas associações, pertencentes aos segmentos da indústria marítima brasileira. Esse universo foi obtido através das associações de classe no Brasil, SINAVAL (associação dos estaleiros dos segmentos da construção naval, plataforma/UEP e reparo naval) e ACOBAR (associações de estaleiros e empresas fornecedoras de peças, componentes e serviços relacionados com o segmento da construção náutica, turismo, esporte e lazer no Brasil).

Os estaleiros visitados pessoalmente possuem excelente representatividade em cada setor de atuação, tanto no cenário nacional como internacional. $\mathrm{Na}$ indústria militar naval, a pesquisa em campo foi realizada na Marinha do Brasil, mais especificamente no Arsenal da Marinha do Rio de Janeiro.

Embarcação produzida basicamente de madeira e considerada de baixo valor agregado, em termos de componentes, não fez parte desta pesquisa.

A população total dos estaleiros dos quatro segmentos pesquisados no Brasil é de 43 estaleiros (20 dos segmentos da construção naval e offshore e 20 da construção náutica). Nesta pesquisa os estaleiros não visitados pessoalmente para coleta de dados representaram dois estaleiros do setor da construção naval que no momento estavam sem produção e praticamente desativados e sete estaleiros de pequeno porte do segmento da construção náutica, que representam a fabricação de produtos de lazer de baixo valor agregado e com pouquíssima representatividade em termos de volume de vendas no Brasil e sem representatividade na exportação. Portanto, as partes mais representativas dos segmentos foram pesquisadas, em termos de volume de produção e faturamento.

No segmento apenas de plataforma são cinco estaleiros no Brasil e todos foram visitados; no de reparo naval existem cinco estaleiros, e todos também foram visitados. No segmento de construção naval são 10 estaleiros: sete foram visitados, dois estavam praticamente desativados e apenas um não recebeu o pesquisador.

No segmento da construção náutica são 20 estaleiros e 14 foram visitados, representando a totalidade de produtos de alto valor agregado, iates de luxo e também a totalidade de produtos com valores inferiores aos de iates de luxo, como lanchas, veleiros etc. A maioria dos sete estaleiros não visitados pelo pesquisador representam a produção de produtos para o segmento específico de lazer, pequenas embarcações de pouquíssimo valor agregado.

\section{Associação dos fatores críticos de sucesso (FCSs) com as dimensões (custos, qualidade, flexibilidade, tempo, credibilidade e inovação)}

A associação dos fatores críticos de sucesso (FCSs) com as dimensões da indústria marítima brasileira foi realizada por meio da técnica estatística 
Tabela 2. Análise de resíduos da tabela de contingência usada na análise de correspondência.

\begin{tabular}{|c|c|c|c|c|c|c|}
\hline Questão & Qualidade & Custos & Inovação & Flexibilidade & Tempo & Credibilidade \\
\hline F1 & 0,78 & 1,76 & $-1,16$ & $-0,14$ & $-1,39$ & $-1,40$ \\
\hline F2 & 0,42 & 0,45 & $-1,16$ & $-0,14$ & 0,95 & $-1,40$ \\
\hline F3 & $-1,04$ & 2,63 & $-1,79$ & $-0,14$ & 0,95 & $-1,40$ \\
\hline $\mathrm{F} 4$ & 1,51 & $-2,60$ & 5,13 & $-1,11$ & $-1,97$ & $-1,40$ \\
\hline F5 & 0,78 & 1,32 & 0,09 & $-0,14$ & $-1,97$ & $-1,40$ \\
\hline F6 & 3,33 & $-1,73$ & $-0,54$ & $-1,11$ & $-0,81$ & $-1,40$ \\
\hline F7 & 3,70 & $-2,60$ & $-0,54$ & 1,78 & $-1,97$ & $-1,40$ \\
\hline F8 & 2,60 & $-2,60$ & 3,24 & $-1,11$ & $-1,97$ & $-1,40$ \\
\hline F9 & 1,88 & 0,45 & $-0,54$ & $-1,11$ & $-1,39$ & $-1,40$ \\
\hline F10 & $-3,59$ & 3,50 & $-1,79$ & $-1,11$ & $-1,97$ & 7,18 \\
\hline F11 & $-0,31$ & 3,06 & $-1,79$ & $-0,14$ & $-0,81$ & $-1,40$ \\
\hline F12 & 1,51 & 0,88 & $-1,79$ & 0,82 & $-1,97$ & $-0,62$ \\
\hline F13 & $-0,31$ & $-2,60$ & $-1,79$ & 2,74 & $-1,39$ & 7,18 \\
\hline F14 & 0,42 & $-2,17$ & $-1,79$ & 0,82 & $-1,97$ & 7,18 \\
\hline F15 & $-1,04$ & $-2,60$ & $-1,79$ & 2,74 & $-0,22$ & 7,18 \\
\hline F16 & $-2,86$ & $-2,17$ & $-0,54$ & 4,67 & 2,70 & 3,28 \\
\hline F17 & $-3,95$ & $-1,29$ & 10,17 & $-0,14$ & $-0,22$ & $-1,40$ \\
\hline F18 & $-2,13$ & $-2,60$ & 0,09 & 0,82 & 7,37 & $-1,40$ \\
\hline F19 & $-1,77$ & 0,01 & 1,35 & $-1,11$ & 3,28 & $-1,40$ \\
\hline F20 & $-3,59$ & 0,88 & $-0,54$ & $-0,14$ & 6,20 & $-1,40$ \\
\hline F21 & 4,06 & $-2,60$ & $-0,54$ & 0,82 & $-1,97$ & $-1,40$ \\
\hline F22 & $-4,68$ & $-2,60$ & $-1,16$ & $-0,14$ & 13,21 & $-1,40$ \\
\hline F23 & $-2,13$ & $-2,60$ & $-1,16$ & $-1,11$ & 9,70 & $-1,40$ \\
\hline F24 & 3,33 & 0,01 & $-1,79$ & $-1,11$ & $-1,97$ & $-1,40$ \\
\hline F25 & 2,97 & $-0,86$ & $-1,79$ & $-0,14$ & $-0,81$ & $-1,40$ \\
\hline F26 & 5,15 & $-2,17$ & $-1,79$ & $-1,11$ & $-1,97$ & $-1,40$ \\
\hline F27 & 1,51 & $-0,86$ & $-1,16$ & 1,78 & $-0,22$ & $-1,40$ \\
\hline F28 & 0,42 & 3,06 & $-1,79$ & $-1,11$ & $-1,39$ & $-1,40$ \\
\hline F29 & $-3,95$ & $-3,04$ & $-1,79$ & 1,78 & 0,95 & 13,43 \\
\hline F30 & $-3,22$ & 5,68 & $-1,79$ & $-1,11$ & 0,95 & $-1,40$ \\
\hline F31 & 5,88 & $-3,04$ & $-1,79$ & $-1,11$ & $-1,97$ & $-1,40$ \\
\hline F32 & 5,88 & $-3,04$ & $-1,79$ & $-1,11$ & $-1,97$ & $-1,40$ \\
\hline F33 & $-5,41$ & $-3,04$ & 17,10 & $-0,14$ & $-1,97$ & $-1,40$ \\
\hline F34 & 0,78 & $-2,60$ & 6,39 & $-1,11$ & $-1,97$ & $-1,40$ \\
\hline F35 & $-5,04$ & 10,04 & $-1,79$ & $-1,11$ & $-1,97$ & $-1,40$ \\
\hline F36 & $-5,04$ & 9,60 & $-1,79$ & $-0,14$ & $-1,97$ & $-1,40$ \\
\hline F37 & $-5,04$ & 9,60 & $-1,79$ & $-0,14$ & $-1,97$ & $-1,40$ \\
\hline F38 & 2,60 & $-0,42$ & $-1,16$ & 0,82 & $-1,97$ & $-1,40$ \\
\hline F39 & 5,52 & $-3,04$ & $-1,16$ & $-1,11$ & $-1,97$ & $-1,40$ \\
\hline Total & - & - & - & - & - & - \\
\hline
\end{tabular}

multivariada -análise de correspondência (HAIR et al., 2005; PEREIRA, 1999; YANG et al., 2010).

Para realizar a análise, foram utilizados os dados coletados em campo nos 31 estaleiros visitados em todo território brasileiro. Com os dados coletados e analisados estatisticamente gerou-se o mapa de percepção, apresentado na Figura 3, obtido pela análise de correspondência dos fatores críticos de sucesso (FCSs) e suas dimensões.
Para eliminar dúvidas sobre possíveis FCSs associados a mais de uma dimensão (custos, qualidade, flexibilidade, tempo, credibilidade e inovação) utilizou-se a técnica de análise de resíduo, Tabela 2, expressa pela seguinte equação:

Cálculo para o resíduo padronizado

$Z_{r e s}=\frac{O-E}{\sqrt{E} \sqrt{(1-T C / T G)(1-T L / T G)}}$ 
Tabela 3. Frequência relativa (em \%) de respondentes por linha para cada dimensão tangível.

\begin{tabular}{|c|c|c|c|c|c|c|c|}
\hline FCS & Qualidade & Custos & Inovação & Flexibilidade & Tempo & Credibilidade & Total \\
\hline $\mathrm{F} 1$ & 54,84 & 35,48 & 3,23 & 3,23 & 3,23 & 0,00 & 100,00 \\
\hline F2 & 51,61 & 25,81 & 3,23 & 3,23 & 16,13 & 0,00 & 100,00 \\
\hline F3 & 38,71 & 41,94 & 0,00 & 3,23 & 16,13 & 0,00 & 100,00 \\
\hline F4 & 61,29 & 3,23 & 35,48 & 0,00 & 0,00 & 0,00 & 100,00 \\
\hline F5 & 54,84 & 32,26 & 9,68 & 3,23 & 0,00 & 0,00 & 100,00 \\
\hline F6 & 77,42 & 9,68 & 6,45 & 0,00 & 6,45 & 0,00 & 100,00 \\
\hline F7 & 80,65 & 3,23 & 6,45 & 9,68 & 0,00 & 0,00 & 100,00 \\
\hline F8 & 70,97 & 3,23 & 25,81 & 0,00 & 0,00 & 0,00 & 100,00 \\
\hline F9 & 64,52 & 25,81 & 6,45 & 0,00 & 3,23 & 0,00 & 100,00 \\
\hline $\mathrm{F} 10$ & 16,13 & 48,39 & 0,00 & 0,00 & 0,00 & 35,48 & 100,00 \\
\hline F11 & 45,16 & 45,16 & 0,00 & 3,23 & 6,45 & 0,00 & 100,00 \\
\hline $\mathrm{F} 12$ & 61,29 & 29,03 & 0,00 & 6,45 & 0,00 & 3,23 & 100,00 \\
\hline $\mathrm{F} 13$ & 45,16 & 3,23 & 0,00 & 12,90 & 3,23 & 35,48 & 100,00 \\
\hline $\mathrm{F} 14$ & 51,61 & 6,45 & 0,00 & 6,45 & 0,00 & 35,48 & 100,00 \\
\hline F15 & 38,71 & 3,23 & 0,00 & 12,90 & 9,68 & 35,48 & 100,00 \\
\hline F16 & 22,58 & 6,45 & 6,45 & 19,35 & 25,81 & 19,35 & 100,00 \\
\hline $\mathrm{F} 17$ & 12,90 & 12,90 & 61,29 & 3,23 & 9,68 & 0,00 & 100,00 \\
\hline $\mathrm{F} 18$ & 29,03 & 3,23 & 9,68 & 6,45 & 51,61 & 0,00 & 100,00 \\
\hline F19 & 32,26 & 22,58 & 16,13 & 0,00 & 29,03 & 0,00 & 100,00 \\
\hline F20 & 16,13 & 29,03 & 6,45 & 3,23 & 45,16 & 0,00 & 100,00 \\
\hline F21 & 83,87 & 3,23 & 6,45 & 6,45 & 0,00 & 0,00 & 100,00 \\
\hline F22 & 6,45 & 3,23 & 3,23 & 3,23 & 83,87 & 0,00 & 100,00 \\
\hline F23 & 29,03 & 3,23 & 3,23 & 0,00 & 64,52 & 0,00 & 100,00 \\
\hline F24 & 77,42 & 22,58 & 0,00 & 0,00 & 0,00 & 0,00 & 100,00 \\
\hline F25 & 74,19 & 16,13 & 0,00 & 3,23 & 6,45 & 0,00 & 100,00 \\
\hline F26 & 93,55 & 6,45 & 0,00 & 0,00 & 0,00 & 0,00 & 100,00 \\
\hline F27 & 61,29 & 16,13 & 3,23 & 9,68 & 9,68 & 0,00 & 100,00 \\
\hline F28 & 51,61 & 45,16 & 0,00 & 0,00 & 3,23 & 0,00 & 100,00 \\
\hline F29 & 12,90 & 0,00 & 0,00 & 9,68 & 16,13 & 61,29 & 100,00 \\
\hline F30 & 19,35 & 64,52 & 0,00 & 0,00 & 16,13 & 0,00 & 100,00 \\
\hline F31 & 100,00 & 0,00 & 0,00 & 0,00 & 0,00 & 0,00 & 100,00 \\
\hline F32 & 100,00 & 0,00 & 0,00 & 0,00 & 0,00 & 0,00 & 100,00 \\
\hline F33 & 0,00 & 0,00 & 96,77 & 3,23 & 0,00 & 0,00 & 100,00 \\
\hline F34 & 54,84 & 3,23 & 41,94 & 0,00 & 0,00 & 0,00 & 100,00 \\
\hline F35 & 3,23 & 96,77 & 0,00 & 0,00 & 0,00 & 0,00 & 100,00 \\
\hline F36 & 3,23 & 93,55 & 0,00 & 3,23 & 0,00 & 0,00 & 100,00 \\
\hline F37 & 3,23 & 93,55 & 0,00 & 3,23 & 0,00 & 0,00 & 100,00 \\
\hline F38 & 70,97 & 19,35 & 3,23 & 6,45 & 0,00 & 0,00 & 100,00 \\
\hline F39 & 96,77 & 0,00 & 3,23 & 0,00 & 0,00 & 0,00 & 100,00 \\
\hline Total & - & - & - & - & - & - & - \\
\hline
\end{tabular}

onde:

- 0 = frequência observada;

- $\mathrm{E}$ = frequência esperada;

- $\mathrm{TG}=$ total geral da tabela;

- $\mathrm{TC}=$ total geral da coluna; e

- $\mathrm{TL}=$ total da linha.

Com as informações referentes à análise de resíduo padronizado, foi possível identificar as associações entre os FCSs e suas respectivas dimensões. Além da análise de resíduo utilizou-se também a estatística descritiva, fruto da pesquisa realizada em campo para inferência da associação entre FCSs e sua respectiva dimensão.

Para fazer o mapa perceptual foram utilizadas as informações coletadas da pesquisa em campo e apresentadas nas Tabelas 3, 4 e 5. Com essas informações gerou-se o mapa de percepção, apenas com os FCSs de fato associados somente com uma dimensão, conforme a Figura 4. 
Tabela 4. Frequência relativa (em \%) de respondentes por linha para cada dimensão.

\begin{tabular}{|c|c|c|c|c|c|c|c|}
\hline FCS & Qualidade & Custos & Inovação & Flexibilidade & Tempo & Credibilidade & Total \\
\hline F1 & 54,84 & 35,48 & 3,23 & 3,23 & 3,23 & 0,00 & 100,00 \\
\hline F2 & 51,61 & 25,81 & 3,23 & 3,23 & 16,13 & 0,00 & 100,00 \\
\hline F3 & 38,71 & 41,94 & 0,00 & 3,23 & 16,13 & 0,00 & 100,00 \\
\hline $\mathrm{F} 4$ & 61,29 & 3,23 & 35,48 & 0,00 & 0,00 & 0,00 & 100,00 \\
\hline F5 & 54,84 & 32,26 & 9,68 & 3,23 & 0,00 & 0,00 & 100,00 \\
\hline F6 & 77,42 & 9,68 & 6,45 & 0,00 & 6,45 & 0,00 & 100,00 \\
\hline F7 & 80,65 & 3,23 & 6,45 & 9,68 & 0,00 & 0,00 & 100,00 \\
\hline F8 & 70,97 & 3,23 & 25,81 & 0,00 & 0,00 & 0,00 & 100,00 \\
\hline F9 & 64,52 & 25,81 & 6,45 & 0,00 & 3,23 & 0,00 & 100,00 \\
\hline F10 & 16,13 & 48,39 & 0,00 & 0,00 & 0,00 & 35,48 & 100,00 \\
\hline $\mathrm{F} 11$ & 45,16 & 45,16 & 0,00 & 3,23 & 6,45 & 0,00 & 100,00 \\
\hline $\mathrm{F} 12$ & 61,29 & 29,03 & 0,00 & 6,45 & 0,00 & 3,23 & 100,00 \\
\hline F13 & 45,16 & 3,23 & 0,00 & 12,90 & 3,23 & 35,48 & 100,00 \\
\hline $\mathrm{F} 14$ & 51,61 & 6,45 & 0,00 & 6,45 & 0,00 & 35,48 & 100,00 \\
\hline F15 & 38,71 & 3,23 & 0,00 & 12,90 & 9,68 & 35,48 & 100,00 \\
\hline F16 & 22,58 & 6,45 & 6,45 & 19,35 & 25,81 & 19,35 & 100,00 \\
\hline F17 & 12,90 & 12,90 & 61,29 & 3,23 & 9,68 & 0,00 & 100,00 \\
\hline F18 & 29,03 & 3,23 & 9,68 & 6,45 & 51,61 & 0,00 & 100,00 \\
\hline F19 & 32,26 & 22,58 & 16,13 & 0,00 & 29,03 & 0,00 & 100,00 \\
\hline F20 & 16,13 & 29,03 & 6,45 & 3,23 & 45,16 & 0,00 & 100,00 \\
\hline $\mathrm{F} 21$ & 83,87 & 3,23 & 6,45 & 6,45 & 0,00 & 0,00 & 100,00 \\
\hline $\mathrm{F} 22$ & 6,45 & 3,23 & 3,23 & 3,23 & 83,87 & 0,00 & 100,00 \\
\hline F23 & 29,03 & 3,23 & 3,23 & 0,00 & 64,52 & 0,00 & 100,00 \\
\hline $\mathrm{F} 24$ & 77,42 & 22,58 & 0,00 & 0,00 & 0,00 & 0,00 & 100,00 \\
\hline $\mathrm{F} 25$ & 74,19 & 16,13 & 0,00 & 3,23 & 6,45 & 0,00 & 100,00 \\
\hline F26 & 93,55 & 6,45 & 0,00 & 0,00 & 0,00 & 0,00 & 100,00 \\
\hline $\mathrm{F} 27$ & 61,29 & 16,13 & 3,23 & 9,68 & 9,68 & 0,00 & 100,00 \\
\hline F28 & 51,61 & 45,16 & 0,00 & 0,00 & 3,23 & 0,00 & 100,00 \\
\hline F29 & 12,90 & 0,00 & 0,00 & 9,68 & 16,13 & 61,29 & 100,00 \\
\hline F30 & 19,35 & 64,52 & 0,00 & 0,00 & 16,13 & 0,00 & 100,00 \\
\hline F31 & 100,00 & 0,00 & 0,00 & 0,00 & 0,00 & 0,00 & 100,00 \\
\hline F32 & 100,00 & 0,00 & 0,00 & 0,00 & 0,00 & 0,00 & 100,00 \\
\hline F33 & 0,00 & 0,00 & 96,77 & 3,23 & 0,00 & 0,00 & 100,00 \\
\hline F34 & 54,84 & 3,23 & 41,94 & 0,00 & 0,00 & 0,00 & 100,00 \\
\hline F35 & 3,23 & 96,77 & 0,00 & 0,00 & 0,00 & 0,00 & 100,00 \\
\hline F36 & 3,23 & 93,55 & 0,00 & 3,23 & 0,00 & 0,00 & 100,00 \\
\hline F37 & 3,23 & 93,55 & 0,00 & 3,23 & 0,00 & 0,00 & 100,00 \\
\hline F38 & 70,97 & 19,35 & 3,23 & 6,45 & 0,00 & 0,00 & 100,00 \\
\hline F39 & 96,77 & 0,00 & 3,23 & 0,00 & 0,00 & 0,00 & 100,00 \\
\hline Total & - & - & - & - & - & - & - \\
\hline
\end{tabular}

Dessa forma, constatou-se que alguns fatores críticos de sucesso (FCSs) não estavam necessariamente associados diretamente a apenas uma dimensão (custos, qualidade, flexibilidade, credibilidade, tempo e inovação) e às vezes com baixa aderência a um FCSs. Casos assim foram eliminados do estudo e o foco foi apenas para os FCSs com alta aderência com uma dimensão. Portanto, analisando a Figura 4, mapa de percepção, percebe-se que as dimensões são representadas por triângulos e as pequenas circunferências são os FCSs numerados de F1 até F39 (fatores mais relevantes, segundo os estaleiros domésticos, para avaliar a competitividade dessa indústria).

Uma das grandes vantagens do uso da análise de correspondência está no fato de permitir a explicação das relações existentes entre as variáveis e suas categorias em grandes tabelas de contingência, como é o caso do problema apresentado nesta pesquisa. No entanto, as 
Tabela 5. Frequência relativa (em \%) de respondentes por coluna para cada fator crítico de sucesso.

\begin{tabular}{|c|c|c|c|c|c|c|}
\hline FCS & Qualidade & Custos & Inovação & Flexibilidade & Tempo & Credibilidade \\
\hline $\mathrm{F} 1$ & 2,94 & 4,04 & 0,90 & 2,22 & 0,76 & 0,00 \\
\hline F2 & 2,76 & 2,94 & 0,90 & 2,22 & 3,79 & 0,00 \\
\hline F3 & 2,07 & 4,78 & 0,00 & 2,22 & 3,79 & 0,00 \\
\hline F4 & 3,28 & 0,37 & 9,91 & 0,00 & 0,00 & 0,00 \\
\hline F5 & 2,94 & 3,68 & 2,70 & 2,22 & 0,00 & 0,00 \\
\hline F6 & 4,15 & 1,10 & 1,80 & 0,00 & 1,52 & 0,00 \\
\hline F7 & 4,32 & 0,37 & 1,80 & 6,67 & 0,00 & 0,00 \\
\hline F8 & 3,80 & 0,37 & 7,21 & 0,00 & 0,00 & 0,00 \\
\hline F9 & 3,45 & 2,94 & 1,80 & 0,00 & 0,76 & 0,00 \\
\hline $\mathrm{F} 10$ & 0,86 & 5,51 & 0,00 & 0,00 & 0,00 & 15,71 \\
\hline F11 & 2,42 & 5,15 & 0,00 & 2,22 & 1,52 & 0,00 \\
\hline $\mathrm{F} 12$ & 3,28 & 3,31 & 0,00 & 4,44 & 0,00 & 1,43 \\
\hline $\mathrm{F} 13$ & 2,42 & 0,37 & 0,00 & 8,89 & 0,76 & 15,71 \\
\hline $\mathrm{F} 14$ & 2,76 & 0,74 & 0,00 & 4,44 & 0,00 & 15,71 \\
\hline $\mathrm{F} 15$ & 2,07 & 0,37 & 0,00 & 8,89 & 2,27 & 15,71 \\
\hline F16 & 1,21 & 0,74 & 1,80 & 13,33 & 6,06 & 8,57 \\
\hline $\mathrm{F} 17$ & 0,69 & 1,47 & 17,12 & 2,22 & 2,27 & 0,00 \\
\hline F18 & 1,55 & 0,37 & 2,70 & 4,44 & 12,12 & 0,00 \\
\hline F19 & 1,73 & 2,57 & 4,50 & 0,00 & 6,82 & 0,00 \\
\hline F20 & 0,86 & 3,31 & 1,80 & 2,22 & 10,61 & 0,00 \\
\hline F21 & 4,49 & 0,37 & 1,80 & 4,44 & 0,00 & 0,00 \\
\hline F22 & 0,35 & 0,37 & 0,90 & 2,22 & 19,70 & 0,00 \\
\hline F23 & 1,55 & 0,37 & 0,90 & 0,00 & 15,15 & 0,00 \\
\hline F24 & 4,15 & 2,57 & 0,00 & 0,00 & 0,00 & 0,00 \\
\hline F25 & 3,97 & 1,84 & 0,00 & 2,22 & 1,52 & 0,00 \\
\hline F26 & 5,01 & 0,74 & 0,00 & 0,00 & 0,00 & 0,00 \\
\hline F27 & 3,28 & 1,84 & 0,90 & 6,67 & 2,27 & 0,00 \\
\hline F28 & 2,76 & 5,15 & 0,00 & 0,00 & 0,76 & 0,00 \\
\hline F29 & 0,69 & 0,00 & 0,00 & 6,67 & 3,79 & 27,14 \\
\hline F30 & 1,04 & 7,35 & 0,00 & 0,00 & 3,79 & 0,00 \\
\hline F31 & 5,35 & 0,00 & 0,00 & 0,00 & 0,00 & 0,00 \\
\hline F32 & 5,35 & 0,00 & 0,00 & 0,00 & 0,00 & 0,00 \\
\hline F33 & 0,00 & 0,00 & 27,03 & 2,22 & 0,00 & 0,00 \\
\hline F34 & 2,94 & 0,37 & 11,71 & 0,00 & 0,00 & 0,00 \\
\hline F35 & 0,17 & 11,03 & 0,00 & 0,00 & 0,00 & 0,00 \\
\hline F36 & 0,17 & 10,66 & 0,00 & 2,22 & 0,00 & 0,00 \\
\hline F37 & 0,17 & 10,66 & 0,00 & 2,22 & 0,00 & 0,00 \\
\hline F38 & 3,80 & 2,21 & 0,90 & 4,44 & 0,00 & 0,00 \\
\hline F39 & 5,18 & 0,00 & 0,90 & 0,00 & 0,00 & 0,00 \\
\hline Total & 100,00 & 100,00 & 100,00 & 100,00 & 100,00 & 100,00 \\
\hline
\end{tabular}

poucas unidades amostrais, obtidas da pesquisa em campo, total de 31 estaleiros, e a sua natureza (heterogeneidade entre os segmentos), trouxeram algumas dificuldades de análise e interpretação dos resultados. Essas dificuldades foram trabalhadas pelo exame minucioso dos resultados através do mapa de percepção, da análise de resíduo padronizada e da análise descritiva das frequências de respostas dos estaleiros por segmento.

\section{Mapa dos quadrantes de competitividade}

Foram utilizados os dados de importância declarada dos FCSs para construir um mapa de importância dos quadrantes à indústria marítima brasileira. $\mathrm{Na}$ análise, adotaram-se os dados de avaliação da presença dos fatores críticos de sucesso nos estaleiros pesquisados. A escala de avaliação baseou-se numa escala de discordância/ 
concordância de seis pontos. A interpretação da estratégia de análise assim utilizada está representada na Figura 3.

Para a construção do mapa, as notas de importância e de avaliação dos FCSs foram padronizadas em escores normais e suas correspondentes áreas. Nesse mapa, as linhas contínuas (em preto) representam o ponto médio para cada eixo, importância e avaliação, e as

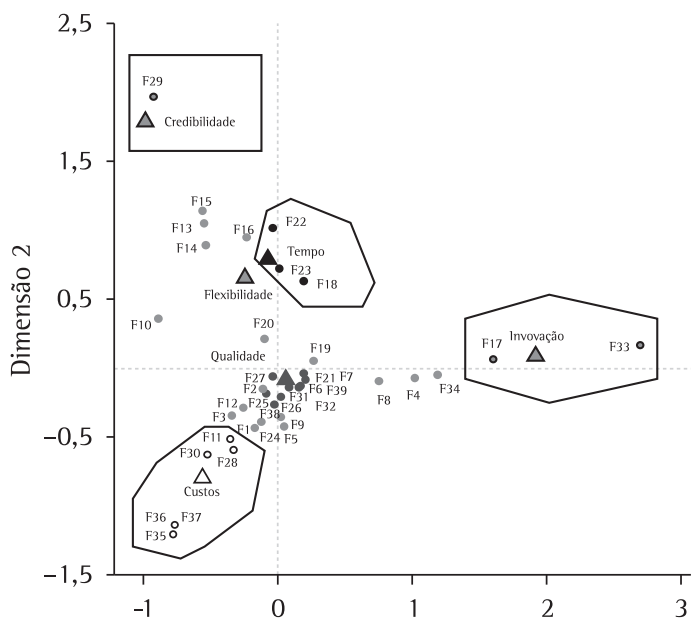

Figura 4. Mapa de percepção. linhas tracejadas permitem identificar os FCSs significantes em cada quadrante do mapa baseado nos limites inferiores e superiores de um intervalo de confiança.

Observa-se, no mapa apresentado, na Figura 5, de forma geral, que os fatores F1, F5, F6, F7, F10, F11, F12, F22, F29, F38, F39 se encontram dentro do quadrante 1. Dessa forma, interpreta-se que esses são pré-requisitos necessários para a indústria marítima brasileira. Já os fatores F8, F19, F26, F30, F33, F34, F35 F36 e F37 estão no quadrante IV. Esses fatores foram considerados muito importantes pelos estaleiros e sua implantação contribuiria bastante para a competitividade da indústria marítima brasileira. Conclui-se que esses fatores se configuram como necessidade de melhoria para o aumento da competitividade da indústria marítima brasileira.

A indústria marítima brasileira está sendo representada pelos quatro segmentos pesquisados (construção naval, construção de plataformas, reparo naval e construção náutica).

Fatores que se enquadram no quadrante 11 (baixa relevância) não são essenciais, de forma geral, para a indústria marítima brasileira, e o mesmo acontece com os fatores do quadrante 111 (neutralidade).

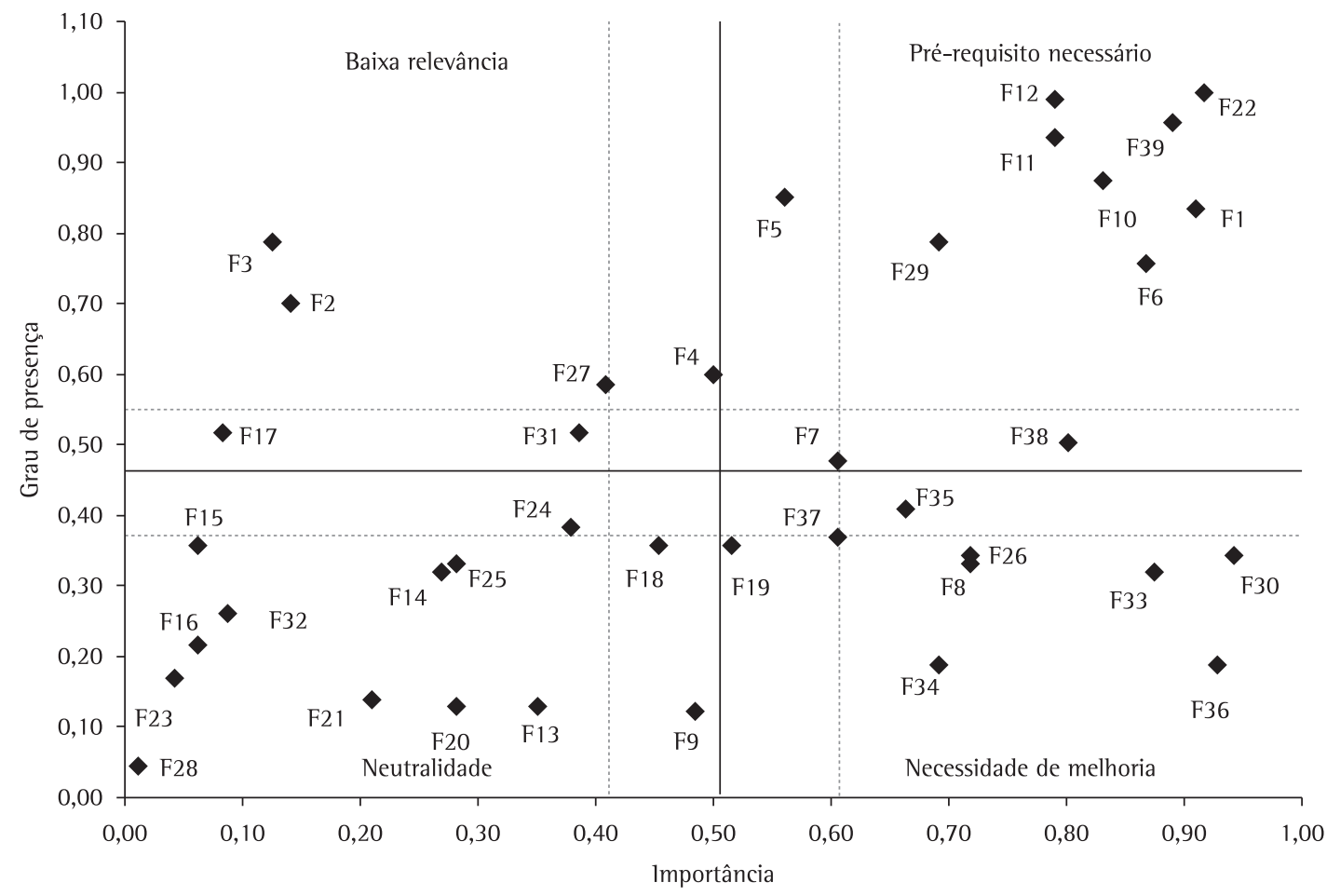

Figura 5. Mapa de necessidade de melhoria e pré-requisito necessário à indústria marítima brasileira. 
Quadro 2. Fatores críticos de sucesso do quadrante pré-requisito necessário da indústria marítima brasileira.

\begin{tabular}{|c|c|}
\hline \multicolumn{2}{|c|}{ Quadrante: Pré-requisito necessário } \\
\hline \multicolumn{2}{|l|}{ FCS: F1 - Sistema de qualificação de fornecedores. } \\
\hline \multicolumn{2}{|l|}{$\begin{array}{l}\text { Ponto forte } \\
\text { - Os segmentos de plataforma/UEP e reparo naval estão mais } \\
\text { particularidades do setor de reparo naval que o diferencia do }\end{array}$} \\
\hline \multicolumn{2}{|l|}{$\mathrm{FC}$} \\
\hline \multicolumn{2}{|c|}{$\begin{array}{l}\text { Ponto forte } \\
\text { - Na maioria dos segmentos da indústria marítima brasileira esse item está em es } \\
\text { aumento de itens nacionais nas embarcações. }\end{array}$} \\
\hline \multicolumn{2}{|l|}{$\mathrm{FC}$} \\
\hline \multicolumn{2}{|c|}{$\begin{array}{l}\text { Ponto fraco } \\
\text { - Com exceção do segmento de plataforma/UEP, os demais segmentos encontram-se desatualizados, na sua maioria de equipamentos } \\
\text { e máquinas. }\end{array}$} \\
\hline \multicolumn{2}{|c|}{ FCS: F7 - Fornecedores participando da fase de desenvolvimento do projeto. } \\
\hline \multicolumn{2}{|c|}{$\begin{array}{l}\text { Ponto fraco } \\
\text { - Com exceção do segmento de plataforma/UEP, os demais segmentos estão em fase considerada de pouca expressão para esse item. }\end{array}$} \\
\hline \multicolumn{2}{|c|}{ FCS: F10 - Forma de mensurar o comprometimento dos fornecedores com o prazo de entrega, através de mecanismos de controle. } \\
\hline $\begin{array}{l}\text { Ponto forte } \\
\text { - Nos segmentos de construção naval e plataforma/UEP esse item } \\
\text { possui alta presença. }\end{array}$ & $\begin{array}{l}\text { Ponto fraco } \\
\text { - Nos segmentos de cons } \\
\text { possui baixa presença. }\end{array}$ \\
\hline \multicolumn{2}{|c|}{ FCS: F11 - Padronização de peças/componentes provenientes fornecedores nacionais. } \\
\hline \multicolumn{2}{|c|}{$\begin{array}{l}\text { Ponto forte } \\
\text { - Na maioria dos segmentos pesquisados há a padronização, com especial atenção ao segmento de plataforma/UEP onde o sistema } \\
\text { de produção é por grandes projetos, e a padronização nem sempre é possivel, pois cada projeto necessita, muitas vezes, de } \\
\text { customização em relação às peças e componentes. } \\
\text { Por outro lado, partes específicas de embarcações não há padronização como itens focados na acomodação, como cozinha } \\
\text { relacionada com o segmento da construção naval. }\end{array}$} \\
\hline \multicolumn{2}{|c|}{ FCS: F12 - Padronização de peças/componentes provenientes fornecedores internacionais. } \\
\hline \multicolumn{2}{|c|}{$\begin{array}{l}\text { Ponto forte } \\
\text { - Há a padronização bem expressiva, exceto novamente ao segmento de plataforma/UEP onde o sistema de produção é por grandes } \\
\text { projetos e há a customização necessária para cada empreendimento realizado. }\end{array}$} \\
\hline \multicolumn{2}{|c|}{ FCS: F22 - Uso do sistema CAD para realizar o desenvolvimento de projetos das embarcações. } \\
\hline \multicolumn{2}{|c|}{$\begin{array}{l}\text { Ponto forte } \\
\text { • Há o uso em larga escala desse tipo de ferramenta para auxílio de desenvolvimento c }\end{array}$} \\
\hline \multicolumn{2}{|l|}{ FCS } \\
\hline \multicolumn{2}{|c|}{$\begin{array}{l}\text { Ponto mediano } \\
\text { - No segmento de plataforma/UEP essa prática não é realizada em larga escala. Nos demais segmentos esse item se encontra numa } \\
\text { fase intermediária de implantação. Há espaço para melhorar esse fator. }\end{array}$} \\
\hline \multicolumn{2}{|l|}{ FCS: F38 - Ser uma empresa exportadora. } \\
\hline \multicolumn{2}{|c|}{$\begin{array}{l}\text { Ponto forte } \\
\text { - Boa parte dos estaleiros pesquisados pretende aumentar a parcela de mercado de produtos exportados ou iniciar a exportação de } \\
\text { seus produtos. }\end{array}$} \\
\hline \multicolumn{2}{|c|}{ FCS: F39 - Possuir certificado internacional que permite inserir os produtos no mercado internacional. } \\
\hline & \\
\hline
\end{tabular}

As interpretações desses mapas são de grande importância, pois permitem visualizar as diferenças presentes nos segmentos pesquisados.

\subsection{Mapa dos quadrantes de competitividade da indústria marítima brasileira}

Os Quadros 2 e 3 apresentam quais são os fatores críticos de sucesso (FCSs) inerentes a cada quadrante denominados pré-requisito necessário e necessidade de melhoria apresentados na Figura 5, assim como os pontos fortes e fracos de cada FCS existentes atualmente na indústria marítima brasileira. Tais informações são frutos da pesquisa realizada em campo para definir os FCSs definidos pelos próprios estaleiros.

0 Quadro 2 relata de forma geral os pontos fortes e fracos dos fatores críticos de sucesso enquadrados no quadrante de competitividade denominado pré-requisito necessário. 
Quadro 3. Fatores críticos de sucesso do quadrante necessidade de melhoria da indústria marítima brasileira.

\section{Quadrante: Necessidade de melhoria}

FCS: F8 - Parceria tecnológica na área de pesquisa e desenvolvimento entre os fornecedores e o estaleiro.

\begin{tabular}{l|l} 
Ponto forte & Ponto fraco
\end{tabular}

- No segmento de plataforma/UEP, esse índice é considerado • É muito pouco o que existe de parceira tecnológica na área de elevado, com grandes oportunidades de aumentar essa integração que beneficie todo o setor (cadeia de suprimentos e estaleiros/UEP). pesquisa e desenvolvimento entre os fornecedores e os estaleiros nacionais na maioria dos segmentos pesquisados.

FCS: F19 - Ter fornecedores internacionais participando da fase de desenvolvimento de projeto.

Ponto forte

- Nos segmentos da construção naval e plataforma/UEP, esse percentual é considerado elevado e bem mais estruturado, devido a características do produto e de sua cadeia de suprimentos.

\section{Ponto fraco}

- Nos segmentos de reparo naval e construção náutica esse índice é baixo, porém cada setor possui suas particularidades e, às vezes, há esta integração apenas com os fornecedores considerados estratégicos, visto que, no setor de construção náutica, boa parte dos fornecedores oferece produtos de catálogo.

FCS: F26 - Ter um programa de qualidade para fornecedores nacionais como forma de melhorar o produto final.

Observação

- A pesquisa em campo apontou estatisticamente que essa prática é muito pouco utilizada pelos estaleiros nacionais, mas eles almejam poder colaborar com suas respectivas cadeias de suprimentos para melhorar a qualidade dos produtos nacionais, porém julgam que não seria algo exclusivamente proveniente da vontade própria, porque há necessidade de implantar políticas industriais que auxiliem a indústria marítima.

FCS: F30 - Mão de obra técnica qualificada no mercado nacional que supra a indústria marítima nacional.

Ponto fraco

- De forma geral, a indústria marítima brasileira não possui mão de obra técnica qualificada para suprir a necessidade do mercado, e para um país se tornar competitivo é necessário ter uma política que elimine ou minimize esse ponto crucial para o crescimento da indústria.

FCS: F33 - Integração entre estaleiro e as universidades nacionais para desenvolvimento de pesquisas.

Ponto forte

- Nos segmentos da construção naval e plataforma/UEP, há essa integração entre universidades e centros de pesquisa do país, porém se pode expandir ainda mais, e as próprias empresas entrevistadas ressaltaram a necessidade da aproximação entre estaleiros/UEP e universidades nacionais.

\section{Ponto fraco}

- Para os segmentos de construção náutica e reparo naval, ainda é incipiente essa integração ou muitas vezes inexistente, como no caso do segmento de reparo naval. Os estaleiros pesquisados manifestaram a necessidade desta integração como benefício mútuo para as empresas e universidades / centros de pesquisa do país.

FCS: F34 - Investimentos nas universidades e escolas técnicas para contribuir na formação do profissional para a indústria marítima.

Ponto forte

- 0 segmento da construção naval investe na formação de mão de obra, como a escola técnica que há no Arsenal da Marinha do Rio de Janeiro, para suprir a necessidade de mão de obra técnica e qualificada para o setor.

\section{Ponto fraco}

- Os demais segmentos não investem em escolas técnicas ou universidades. Há casos isolados de estaleiros, principalmente no segmento da construção náutica, que iniciou parceria com o Senai para preparar mão de obra específica para seu segmento de atuação, devido à escassez existente no mercado e à necessidade de aumentar o volume de produção do estaleiro que estava no gargalo.

FCS: F35 - Existir subsídios ou incentivos governamentais aos estaleiros.

\section{Ponto forte}

- No segmento da construção náutica, a pesquisa apontou que os estaleiros não almejam subsídios governamentais para alavancar o crescimento desse setor especificamente, mas sim que os tributos inseridos sejam reduzidos ou com valores considerados justos.

\section{Ponto fraco}

- Há com maior incidência, os subsídios no segmento da construção naval, porém os próprios estaleiros pesquisados dizem que os subsídios são para os armadores e não para os estaleiros e deveria existir algo específico para eles. 0 mesmo acontece com os segmentos de plataforma/UEP e reparo naval.

FCS: F36 - Políticas industriais voltadas para o segmento de atuação do estaleiro.

\section{Ponto forte}

- No segmento de plataforma/UEP, há claramente políticas industriais para o setor, como é o caso do Prominp.

\section{Ponto fraco}

- Para o segmento de reparo naval, há algo isolado, como alguns benefícios municipais e estaduais; e para os demais segmentos, construção naval e náutica, quase inexistente e de pouca relevância para incentivar o crescimento dos setores.

FCS: F37 - Utilização de recursos do Fundo da Marinha Mercante.

Ponto forte

- Os setores de construção naval e de plataforma/UEP utilizam, porém o beneficiário desse programa é o armador, o proprietário da embarcação e não os estaleiros/UEP.
Ponto fraco

- No segmento da construção náutica, não há esse tipo de incentivo, exceto para um único estaleiro desse setor que também atua no segmento da construção naval. No segmento de reparo naval, também se utiliza pouco desse tipo de recurso. 
0 Quadro 3 resume de forma geral os pontos fortes e fracos dos fatores críticos de sucesso enquadrados no quadrante de competitividade denominado necessidade de melhoria, que é essencial para a competitividade da indústria marítima brasileira.

\section{Conclusão}

A indústria marítima brasileira, que neste trabalho está caracterizada por quatro segmentos específicos, construção naval, construção de plataforma/UEP, reparo naval e construção náutica, esporte, turismo e lazer, necessita de mais integração entre os atores para se tornar competitiva. Esses atores são as próprias associações de classes envolvendo todas as empresas de cada segmento, governo, universidades, centro de pesquisa e desenvolvimento, escolas técnicas, empresas prestadoras de serviços, empresas consideradas líder dos setores e suas respectivas cadeias de suprimentos (CHIA, 2005; KIM, 2005).

A integração entre os atores da indústria marítima brasileira é essencial para o crescimento dos segmentos, para consolidar as empresas, para promover o desenvolvimento do Brasil no cenário internacional, em setores que podem ser promissores para gerar riqueza, como o caso da indústria náutica, do próprio segmento da construção de plataforma.

Há necessidade de ter políticas industriais que contribuam para o desenvolvimento da indústria marítima, pois as poucas existentes não geram efeitos positivos expressivos para a atual indústria (PINTO et al., 2007).

A Coreia do Sul pode servir como exemplo para o Brasil. Eles iniciaram sua inserção no cenário internacional com produtos considerados como imitação, na década de 70, e hoje estão ofertando produtos mundialmente considerados de alta inovação. Para isso, foram necessários investimentos corretos na área de educação, intensa promoção de incentivos para a exportação, que foi um fator crucial para o sucesso do modelo coreano, e participação integrada de universidades, centros de pesquisa e desenvolvimento, empresas, associações de classes, governo, para levar o país a ocupar posição destacada no mercado internacional, principalmente o segmento da construção naval (KIM, 2005; PIRES JUNIOR; LAMB, 2008; LEE; MARVEL, 2009).

Atualmente há o Prominp no Brasil, Programa de Mobilização da Indústria Nacional de Petróleo e
Gás Natural, utilizado principalmente no segmento da construção de plataforma/UEP. Esse modelo poderia ser expandido para os demais segmentos da indústria marítima brasileira para promover a competitividade dos setores. Poderia também ser utilizado um mix entre o modelo Prominp e os modelos de clusters marítimos implantados na Europa, para alavancar os negócios no Brasil e tornar o país competitivo (TALLMAN et al., 2004; LANGEN, 2002).

Parceria entre universidades, empresas, centros de pesquisa e desenvolvimento é ainda muito incipiente no cenário nacional, com exceção da Petrobras, que promove essa integração atualmente, quase nada mais existe que contribua para o desenvolvimento da cadeia de suprimentos dos estaleiros e possa tornar o Brasil competitivo em nichos específicos da indústria marítima mundial. Outros países implantaram com sucesso sistemas de integração entre os atores de determinadas indústrias e obtiveram sucesso em seus negócios (LAHNSTEIN, 2004; SÖLVELL; KETLES; LINDQVIST, 2008).

A integração entre os elos da cadeia de suprimentos, de infraestrutura, suporte e serviço da indústria marítima pode trazer benefícios para a qualidade do produto, para melhoria dos custos, para redução dos prazos de entrega, para a credibilidade da entrega no prazo acordado entre as partes, para a redução do tempo de produção e projetos das embarcações, para a flexibilidade de produtos, processos e serviços, e pode ainda auxiliar na inovação de produtos e serviços competitivos para os mercados internos e externos (FUGATE, 2006; REICHHART; HOLWEG, 2008; WILKNER; TANG, 2008; WATTS; MABERT; HARTMAN, 2008; ELANG0, 2008).

0 Brasil possui uma oportunidade excelente que poderá inserir o país em nichos específicos no cenário internacional de produtos e serviços relacionados com a indústria marítima, mas para isso há necessidade de muito mais integração entre os atores da indústria marítima nacional, assim como políticas industriais eficientes e eficazes.

Essa pesquisa descreve os fatores críticos de sucesso e a associação de suas respectivas dimensões para avaliar a competitividade da indústria marítima nacional, caracterizada pelos quatro segmentos (construção naval, reparo naval, construção de plataforma e construção náutica).

Pesquisas futuras poderão explorar a sinergia entre esses quatro segmentos brasileiros visando 
analisar a competência central de cada um e o desenvolvimento de projetos em conjunto (envolvendo todos os estaleiros, independente de seu segmento de atuação). 0 foco seria aumentar a competitividade nacional e reduzir a dependência por produtos e serviços importados, numa indústria que movimenta milhões de dólares e que ainda o Brasil possui uma dependência grande de produtos de alto valor agregado provenientes do exterior (MAN; ROIJAKKERS; GRAAUW, 2010).

\section{Referências}

AMBERG, M.; FISCHL, F.; WIENER, M. Background of critical success factor research. 2005. Working Papper, n. 2.

BABBIE, E. Métodos de pesquisa de survey. Belo Horizonte: Ed. UFMG, 2001.

BERGERON, F.; BEGIN, C. The use of critical success factors in evaluation of information systems: a case study. Journal of Management Information Systems, v. 5, n. 4, 1989.

BOLWIJN, P. T.; KUMPE, T. Manufacturing in the 1990's - productivity, flexibility and innovation. Long Range Planning, v. 23, n. 4, p. 47-57, 1990.

BOTELHO, D.; ZOUAIN, D. M. (Org.). Pesquisa quantitativa em administração. São Paulo: Atlas, 2006.

CHIA, S. Y. The Singapore model of industrial policy: past evolution and current thinking. Buenos Aires, Argentina: Singapore Institute of International Affairs; LAEBA Latin America/Caribbean and Asia/Pacific Economics and Business Association, 2005.

COOPER, D.; SCHINDLER, P. Métodos de pesquisa em administração. 7. ed. Porto Alegre: Bookman, 2003.

DANIEL, B. R. Management information crisis. Harvard Business Review, p. 111-121, 1961.

ELANGO, B. Using outsourcing for strategic competitiveness in small and medium-sized firms. Competitiveness Review. International Business Journal, v. 18, n. 4, p. 322-332, 2008.

FERDOWS, K., DE MEYER, A. Lasting improvements in manufacturing performance: in search of a new theory. Journal of Operations Management, v. 9, n. 2, p. 168-185, 1990. http://dx.doi.org/10.1016/02726963(90)90094-T

FLEISCHER, M. et al. Shipbuilding supply chain integration project. Environmental Research Institute of Michigan, 1999. Final report.

FUGATE, B.; SAHIN, F.; MENTZER, J. T. Supply Chain Management Coordination Mechanisms. Journal of Business Logistics, v. 27, n. 2, 2006. http://dx.doi. org/10.1002/j.2158-1592.2006.tb00220.x

HAIR, J. F. et al. Análise multivariada de dados. 5. ed., Porto Alegre: Bookman, 2005.

HAYES, R. H.; WHELLWRIGHT, S. C. Restoring our competitive edge: competitive through manufacturing. New York: John Wiley and Sons, 1984.

KATHURIA, R.; JOSHI, M. P.; DELLANDE, S. International growth strategies of service and manufacturing firms: the case of banking and a chemical industries.
International Journal of Operations \& Production Management, v. 28, n. 10, p. 968-990, 2008. http://dx.doi.org/10.1108/01443570810903113

KIM, L. Da imitação à inovação: a dinâmica do aprendizado tecnológico da Coréia. Campinas, SP: Ed. Unicamp, 2005.

KING, S. F.; BURGESS, T. F. Beyond critical success factors: a dynamic model of enterprise system innovation. International Journal of Information Management, v. 26, n. 1, p. 59-69, 2006. http://dx.doi.org/10.1016/j. ijinfomgt.2005.10.005

LAHNSTEIN, E. Development in the norwegian maritime cluster. In: EUROPEAN MARITIME CLUSTER ORGANISATION ROUNDTABLE, 1., 2004, Wassenaar, Netherlands. Proceedings...

LANGEN, P. W. Clustering and performance; the case of maritime clustering in the Netherlands. Maritime Policy and Management, v. 29, n. 3, p. 209-221, 2002.

LEE, 1. H.; MARVEL, M. R. The moderating effects of home region orientation on $r \& d$ investment and international sme performance: lesson from Korea. European Management Journal, n. 27, p. 316-326, 2009. http://dx.doi.org/10.1016/j.emj.2009.04.011

LEIDECKER, J. K.; BRUNO, A. V. Identifying and using critical success factors. Long Range Planning, London, v. 17, p. 23, 1984. http://dx.doi.org/10.1016/00246301(84)90163-8

MAGNANI, M. Identificação de fatores críticos de sucesso para formulação de estratégias que minimizem a perda de competência organizacional de um centro de $P \& D$ agropecuário. Tese (Doutorado)-Universidade Federal de Santa Catarina, Santa Catarina, 2004.

MAIA, J. L.; CERRA, A. L.; ALVES FILHO, A. G. Inter-relações entre estratégia de operações e gestão da cadeia de suprimentos: estudos de caso no segmento de motores para automóveis. Gestão e Produção, v. 12, n. 3, p. 377$391,2005$.

MAN, A-P.; ROIJAKKERS, N.; GRAAUW, H. Managing dynamics through robust alliance governance structures: the case of $\mathrm{klm}$ and northwest airlines. European Management Journal, v. 28, p. 171-181, 2010. http://dx.doi.org/10.1016/j.emj.2009.11.001

MARCHAND, M.; RAYMOND, L. Researching performance measurement systems: an information systems perspective. International Journal of Operations \& Production Management, v. 28, n. 7, p. 663-686, 2008. http://dx.doi.org/10.1108/01443570810881802

MATTAR, F. N. Pesquisa de marketing: metodologia planejamento. São Paulo: Atlas, 1999. v. 1-2.

MORAES, E. A. Inovação e competitividade: uma proposta de redefinição da importância e escopo da inovação no modelo de estratégia competitiva baseado em competências cumulativas. Dissertação (Mestrado)-FGV/ EAESP, São Paulo, 2003.

MYERS, J. H. Segmentation and positioning for strategic marketing decisions. Chicago: American Marketing Association, 1996.

PEREIRA, J. C. R. Análise de dados qualitativos: estratégias metodológicas para as Ciências da Saúde, Humanas e Sociais. São Paulo: Edusp, 1999.

PINTO, M. et al. Avaliação do desempenho financeiro dos estaleiros mundiais a partir de diferentes estratégias produtivas. In: COPINAVAL, 20., São Paulo, 2007. Anais... 
PIRES JUNIOR, F. C. M.; LAMB, T. Establishing performance targets for shipbuilding policies. Maritime Policy and Management, v. 35, n. 5, p. 491-502, 2008.

PRAJOSO, D. 1.; McDERMOTT, P.; GOH, M. Impact of value chain activities on quality and innovation. International Journal of Operations \& Production Management, v. 28, n. 7, p. 615-635, 2008. http://dx.doi.org/10.1108/01443570810881785

PUTRI, N. T.; YUSOF, S. M. Critical success factors for implementing quality engineering tools and techniques in malaysian's and indonesian's automotive industries: An Exploratory Study. In: INTERNATIONAL MULTICONFERENCE OF ENGINEERS AND COMPUTER SCIENTISTS, 2., 2009, Hong Kong. Proceedings...

QUINTELLA, H. L. M. M.; ROCHA, H. M.; ALVES, M. F. Projetos de veículos automotores. Revista Produção, v. 15, n. 3, p. 334-346, 2005.

REICHHART, A.; HOLWEG, M. Co-located supplier clusters: forms, functions and theoretical perspectives. International Journal of Operations \& Production Management, v. 28, n. 1, p. 53-78, 2008. http://dx.doi. org/10.1108/01443570810841103

ROCKART, J. F. Chief executives define their own data needs. Harvard Business Review, p. 81-93, 1979.

SALAHELDIN, S. 1. Critical success factors for tqm implementation and their impact on performance of smes. International Journal of Productivity and Performance Management, v. 58, n. 3, p. 215-237, 2009. http://dx.doi.org/10.1108/17410400910938832

SELLTIZ, C.; WRIGHTSMAN, L.; COOK, S. Métodos de pesquisa nas relações sociais. São Paulo: EPU, 1987.
SKINNER, W. Manufacturing - missing link in corporate strategy. Harvard Business Review, p. 136-145, 1969.

SLACK, N. Vantagem competitiva em manufatura: atingindo competitividade nas operações industriais. São Paulo: Atlas, 1993.

SÖLVELL, 0.; KETLES, C.; LINDQVIST, G. Industrial specialization and regional clusters in the new EU member states. Competitiveness Review. An International Business Journal, v. 18, n. 1-2, p. 104-130, 2008.

TALLMAN, S. et al. Knowledge, clusters, and competitive advantage. Academy of Management Review, v. 29, n. 2, p. 258-271, 2004.

TONTINI, G.; SANT'ANA, A. J. R. Identificação de atributos críticos de satisfação em um serviço através da análise competitiva do gap de melhoria. Gestão e Produção, v. 14, n. 1, p. 43-54, 2007. http://dx.doi.org/10.1590/ S0104-530X2007000100005

WATTS, C. A.; MABERT, V. A.; HARTMAN, N. Supply chain bolt-ons: investment and usage by manufactures. International Journal of Operations \& Production Management, v. 28, n. 12, p. 1219-1243, 2008. http://dx.doi.org/10.1108/01443570810919378

WILKNER, J.; TANG, 0. A structural framework for closedloop supply chains. The International Journal of Logistics Management, v. 19, n. 3, p. 344-366, 2008. http://dx.doi.org/10.1108/09574090810919198

YANG, C.-L. et al. Mediated effect of environmental management on manufacturing competitiveness: an empirical study. International Journal of Production Economics, v. 123, p. 210-220, 2010. http://dx.doi. org/10.1016/j.ijpe.2009.08.017

\title{
Analysis of competitiveness in Brazilian maritime industry - the associating critical success factors with their dimensions
}

\begin{abstract}
This study examines the competitiveness of the Brazilian maritime industry segment focused on shipbuilding, ship repair, construction of platform / FPSO construction and boating, tourism, leisure and recreation. The study tries to define the critical factors of success in Brazil's maritime industry and draws associations among their respective dimensions. The Models of dimensions proposed by Slack (1993), and Bolwijn and Kumpe (1990) were used as parameters. Field surveys were performed in thirty-one Brazilian shipyards searching for associations among the critical factors of success with the dimensions defined in the literature and the stage of competitiveness of the Brazilian maritime industry was analyzed. Among the main conclusions is the fact that there are particular niches that make Brazil competitive and promote the domestic shipping industry's growth.
\end{abstract}

Keywords

Brazilian maritime industry. Competitiveness. Critical success factors. 